\title{
Estimation of Floatline Height of Trammel and Semi-trammel Net*1
}

\author{
Loel P. Losanes, ${ }^{* 2}$ Ko Matuda, ${ }^{* 2}$ and Atsushi Koike*2 \\ (Received November 15, 1989)
}

\begin{abstract}
Matuda's approximate formula for predicting the floatline height of gillnet was modified in estimating the floatline height of trammel net and semi-trammel net. The estimated values were compared with the actual values obtained from a flume tank experiment using a cross-section of actual nets. For trammel net, Matuda's method was applied by modifying the drag coefficient and weight of netting in water. The same modifications were applied to semi-trammel net when the current comes from the direction of the small-meshed net (the net is of a concave shape similar to a trammel net). In the case when the current comes from the direction of large-meshed net of semi-trammel net (the net is of a parabolic shape), the estimated values of the net of concave shape taken from Matuda's modified formula was used to predict the floatline height of the net of parabolic shape through regression estimates. The resulting estimated values were found to be in close agreement with the actual values.
\end{abstract}

One of the most important factors that affects the efficiency of the trammel and semi-trammel net is the floatline height. To maintain the proper floatline height which can effectively block a certain species of fish at a given current speed is imperative in attaining a high catching efficiency. Fishermen and gear technologists are aware of this fact in designing a net to catch a certain kind of fish. The net is almost always related to the speed of current, the surplus buoyancy and, of course, the height of netting used.

For bottom gillnets, measurements of floatline height have been done in the sea by fishermen through diving, and by scientists using self-recording manometers as was done by Stewart. ${ }^{12}$ Likewise, floatline heights of gillnets with different mesh size, length and twine diameter have been observed in a flume tank by Stewart and Ferro. ${ }^{22}$

Since sophisticated instruments such as selfrecording manometers or flume tanks are not usually available, predicting the height of net with accuracy using a practical formula is a viable alternative. Fridman ${ }^{3)}$ and Matuda $^{4)}$ have used approximate formulas in estimating floatline heights of gillnets set perpendicular to a current. The latter method estimated the floatline height of gillnet from given parameters such as netting material, mesh size, hanging ratio, twine size, float and floatline size, float buoyancy, etc. In this paper, Matuda's approximate formula was applied to estimate the floatline height of trammel and semi-trammel net accurately by making some modifications of the formula and by applying a more suitable estimation for the drag coefficient of netting. The purpose of this study is to adapt a formula which can predict the floatline height of semi-trammel and trammel net with precision.

\section{Materials and Methods}

\section{Flume Tank Experiment}

Three types of nets were used for the experiment; gillnet, semi-trammel net and trammel net. The nets were set in a $17 \times 6.1 \times 2.6 \mathrm{~m}$ flume tank (observation section is $7 \times 1.45 \times 1.2 \mathrm{~m}$ ) and were subjected to the same current speed and buoyancy (number of floats). A rigid rod was used as a floatline to obtain a uniform height. Current speed was measured using a propeller type current meter. The floatline height was first measured at still water when the floatline is in-line vertically with the sinkerline and then from the fastest to the slowest current speed using an optical sight mounted in a graduated vertical tube. Measurement was done with the sinkerline set as the initial point of origin.

In the case of semi-trammel net, it was set at two different directions; with the current coming from the direction of the small-meshed net and vice-versa (current coming from the direction of

*1 An outline of this study was presented at the annual meeting of the Japanese Society of Scientific Fisheries in April 1990, Tokyo.

*2 Department of Marine Science and Technology, Tokyo University of Fisheries, Konan, Minato, Tokyo 108, Japan (L. P. Losanes, 烃田 波, 小池 篤: 東京水産大学海洋生痤学科). 
Table 1. Specification of materials used in flume tank experiment

\begin{tabular}{|c|c|c|c|}
\hline & Float & Rod & Twine \\
\hline Diameter $(\mathrm{cm})$ & 2 & 0.48 & 0.18 \\
\hline Length (cm) & 10 & 135 & 135 \\
\hline $\begin{array}{l}\text { Weight in } \\
\text { water }(\mathrm{g})\end{array}$ & -20 & 24 & 1 \\
\hline Material & $\begin{array}{l}\text { Foam- } \\
\text { plastic }\end{array}$ & FRP & $\begin{array}{c}\text { Cremona } \\
\text { (PVA) }\end{array}$ \\
\hline & $\begin{array}{c}\text { Small- } \\
\text { meshed } \\
\text { net }\end{array}$ & Netting* & $\begin{array}{l}\text { Large- } \\
\text { meshed } \\
\text { net }\end{array}$ \\
\hline Diameter (cm) & .031 & & .043 \\
\hline Mesh size $(\mathrm{cm})$ & 5.1 & & 18.2 \\
\hline Material & Nylon & & Nylon \\
\hline $\begin{array}{l}\text { Hang-in } \\
\quad \text { ratio }(\%)\end{array}$ & 60 & & 41 \\
\hline
\end{tabular}

the large-meshed net). Specifications of the nets are shown in Table 1.

\section{Average Current Speed}

Prior to the the experiment, the average current speed was measured at different depths of the flume tank. This was done to avoid the effects of the bottom boundary layer and any discrepancy due to the walls of the fiume tank, etc. Measurement was carried out by taking the speed at $10 \mathrm{~cm}$ interval from the bottom to the surface of the flume tank using a propeller type electric current meter. Consequently, four different average current speeds were utilized for the net experiment: $5.6,7.6,9.8$, and $14.3 \mathrm{~cm} / \mathrm{s}$. It should be noted that these current speeds were within the range of the actual current speed in the fishing ground where the three types of nets are used.

\section{Results and Discussion}

\section{Shape of Netting}

The shapes of gillnet, semi-trammel net and trammel net are shown in Fig. 1. In this figure, the net with buoyancy similar to the actual net is shown. The semi-trammel net assumes two types of shape, one is of a concave shape which is similar to a trammel net (hereinafter referred to as concave shape) while the other is similar to a parabolic curve (hereinafter referred to as parabolic shape). The floatline height and netting shape of semitrammel net was discussed in detail by Losanes et al..$^{5)}$
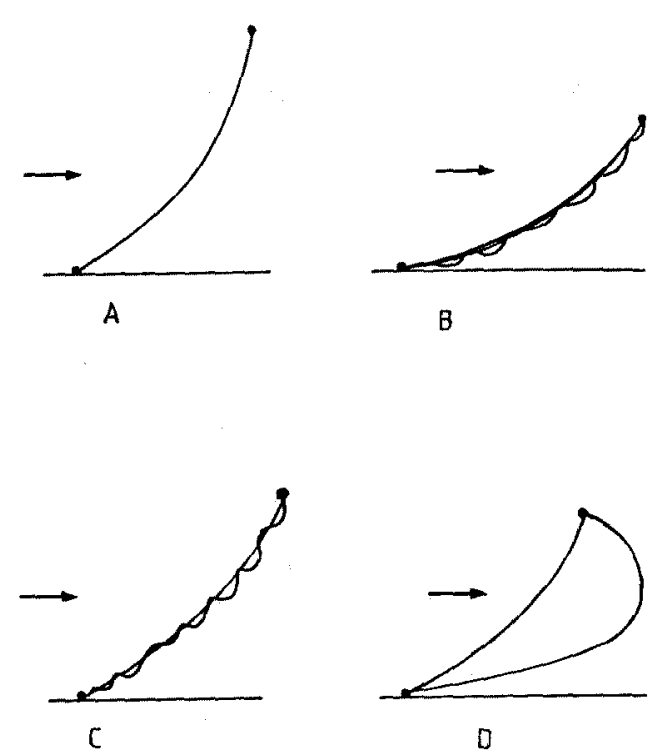

Fig. 1. Cross-sectional shape of gillnet (A), trammel net (B) and semi-trammel net when it assumes a concave shape (C) and a parabolic shape (D).

\section{Estimating the Floatline Height of Net}

Matuda ${ }^{4)}$ derived a formula to predict the floatline height of bottom gillnet set across a water flow from estimates of a cross-sectional shape calculated numerically from differential equations describing the forces of the net. This approximate formula is

$$
h / l=(2 B-w l) / \sqrt{(2 b+k l)^{2} U^{4}+(2 B-w l)^{2}}
$$

where $h(\mathrm{~m})$ is the floatline height, $l(\mathrm{~m})$ the depth of rigged net, $B(\mathrm{~N} / \mathrm{m})$ the buoyancy of floatline, $w\left(\mathrm{~N} / \mathrm{m}^{2}\right)$ the weight of the net webbing in water, $b\left(\mathrm{~kg} / \mathrm{m}^{2}\right)$ the drag coefficient of the floatline, $k$ $\left(\mathrm{kg} / \mathrm{m}^{3}\right)$ the drag coefficient of the net webbing and $U(\mathrm{~m} / \mathrm{s})$ the mean speed of the water flow within the net height.

Since the cross-sectional shape of the semitrammel net (when it assumes a concave shape only) and the trammel net has a close similarity to that of a gillnet, Matuda's formula could be applied also to predict their floatline heights. However, the formula could not be applied directly because of the presence of one large-meshed net for semi-trammel net and two large-meshed nets for trammel net. Therefore, there is a need to modify the formula taking into consideration the large-meshed nets. This is possible by assuming that the shape of the nets are very simiar to two overlapping gillnets for the semi-trammel net and 
three overlappong gillnets for the trammel net, hung in a single frame. Overlapping gillnets mean that the large-meshed net and the smallmeshed net are treated independently as individual gillnets rigged in a common floatline and sinkerline. The assumption was satisfied because the crosssectional shape of the trammel and semi-trammel nets (except for net D) in Fig. 1 is more or less similar to that of the gillnet.

Another factor to be considered in modifying the formula is the presence of the vertical slack which is the ratio of the depth of the small-meshed net to the depth of the large-meshed net. The deeper extra netting of the small-meshed net relative to the large-meshed net when rigged to the same floatline height is responsible for the vertical slack. $^{52} \quad$ The deeper the small-meshed net relative to the large-meshed net, the higher is the value of the vertical slack. Considering these factors, $k$ and $w$ from Eq. (1) should be modified for semitrammel and trammel net by treating their values independently for each sheet of netting (like overlapping gillnets). The sum of $k$ and $w$ for each sheet of netting can then give a single value of $k$ and $w$ for semi-trammel or trammel net.

Consequently, in the case of the semi-trammel net, because there are two sheets of netting, $w$ can be modified into

$$
w=w_{0}+w_{i} s
$$

and in the case of the trammel net, because there are three sheets of netting

$$
w=2 w_{0}+w_{0} s
$$

where $w_{0}$ is the weight of the large-meshed net webbing in water, $w_{i}$ the weight of the smallmeshed net webbing in water and $s$ the vertical slack.

Also, assuming that the same condition holds true for obtaining the drag coefficient of the net webbing of the semi-trammel and trammel net, the drag coefficient of the net webbing of the semi-trammel net can be written as

$$
k=k_{0}+k_{i} s
$$

while that of the trammel net is

$$
k=2 k_{0}+k_{i} s
$$

where $k_{0}$ is the drag coefficient of the net webbing of the large-meshed net and $k_{i}$ the drag coefficient of the net webbing of the small-meshed net. According to Matuda, ${ }^{4} k_{0}$ could be obtained by

$$
k_{0}=-\frac{D_{0} C_{D_{0}} \rho}{L_{0} \sin 2 \phi_{0}}
$$

while $k_{i}$ could be obtained by

$$
k_{i}=\frac{D_{i} C_{D i} \rho}{L_{i} \sin 2 \phi_{i}}
$$

where $\rho$ is the density of water, $D_{0}$ and $D_{i}$ the diameter of netting twine, $L_{0}$ and $L_{i}$ the length of one bar of a mesh, $\phi_{0}$ and $\phi_{i}$ half of the angle between two adjacent bars, $C_{D_{0}}$ and $C_{D_{i}}$ the drag coefficient of the netting twine normal to the current, for the large-meshed net and small-meshed net, respectively.

Matuda $^{4}$ used a constant value of the drag coefficient of the netting twine normal to the current as $C_{D}=1.2$. However, this value of $C_{D}$ was not applied for $C_{D_{0}}$ and $C_{D_{i}}$ in the experiment because the current speed used was extremely low and the netting twine was very thin. Instead the value of $C_{D}$, considering these conditions, was derived from the equation of Miyazaki ${ }^{a)}$ which is

$$
C_{D}=16 R_{h}^{-0.28}
$$

Here, $\boldsymbol{R}_{h}$, the Reynold's number based on the hydraulic mean depth of net webbing is $R_{h}=d U / \nu$ where $d$ is the hydraulic mean depth of plane net, $U$ the current speed and $\nu$ the kinematic viscosity. The value of $d$ is found by $d=0.5 L \sin \phi \cos \phi$ where $L$ is the length of one bar of mesh and $\phi$ half of the angle between two adjacent bars.

Eq. (8) was used to get the $C_{D}$ of the largemeshed net $\left(C_{D_{0}}\right)$ and the small-meshed net $\left(C_{D i}\right)$ for both the semi-trammel and trammel net.

\section{Comparison of Estimated to Experimental Floatline Height}

The values of the estimated floatline height for gillnet, trammel net and semi-trammel net with vertical slacks $1.1,1.5$ and 2.0 subjected to different current speeds and buoyancies were plotted against the observed value taken from the flume tank experiment. Fig. 2 shows that the estimated and observed values exhibit a directly proportional relationship for each type of net. Fig. 2 also shows that the relationship between the estimated and observed values for semi-trammel and trammel net does not vary so much with that of the gillnet, indicating that the difference between the estimated and observed values is negligible. Therefore, the modified approximate formula can be applied in predicting the floatline height of the semi-trammel of concave shape and trammel net with satisfactory 

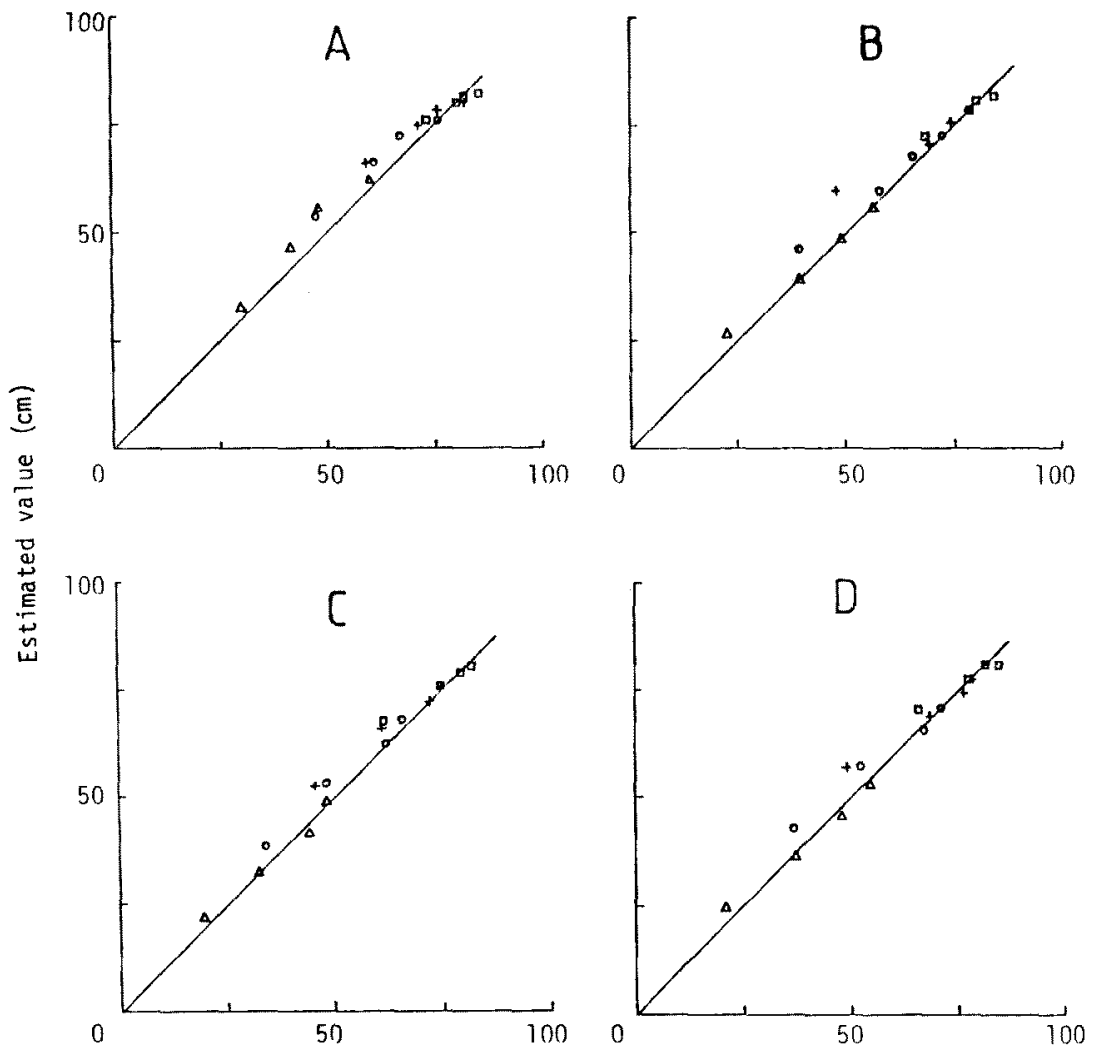

Fig. 2. Relationship between the actual and estimated floatline height of semi-trammel net with vertical slack 1.1 (A), 1.5 (B), and 2.0 (C), gillnet (D), and trammel net (E). Current speed: $\square 5.6$; $+7.6 ; 09.8 ; \triangle 14.3 \mathrm{~cm} / \mathrm{s}$.

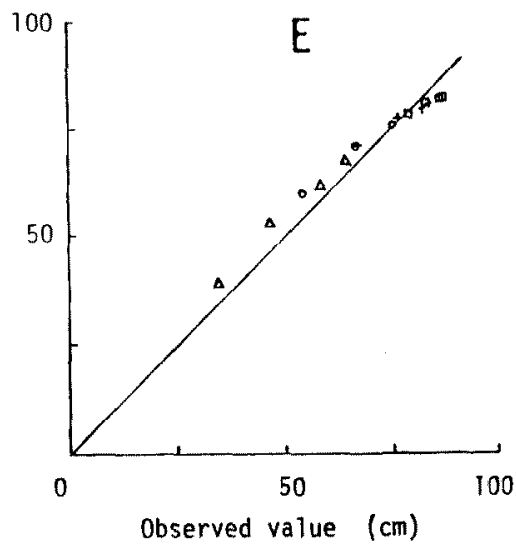

result.

Floatline Height of Semi-trammel Net of Parabolic Shape

A semi-trammel net, depending on the direction of the current, assumes two distinct shapes. One is a concave shape when the current comes from the direction of the small-meshed net and the other is a parabolic shape when the current comes from the direction of the large-meshed net. While the modified approximate formula could be used in predicting the floatline height for semi-trammel net only when its shape is similar to a trammel net (concave shape), the one with the parabolic shape could not be used because it deviates from the assumption of a cross-sectional shape defined by Matuda. ${ }^{4}$

A linear relationship was observed when the observed values of the semi-trammel net of parabolic shape were plotted against those of the net 

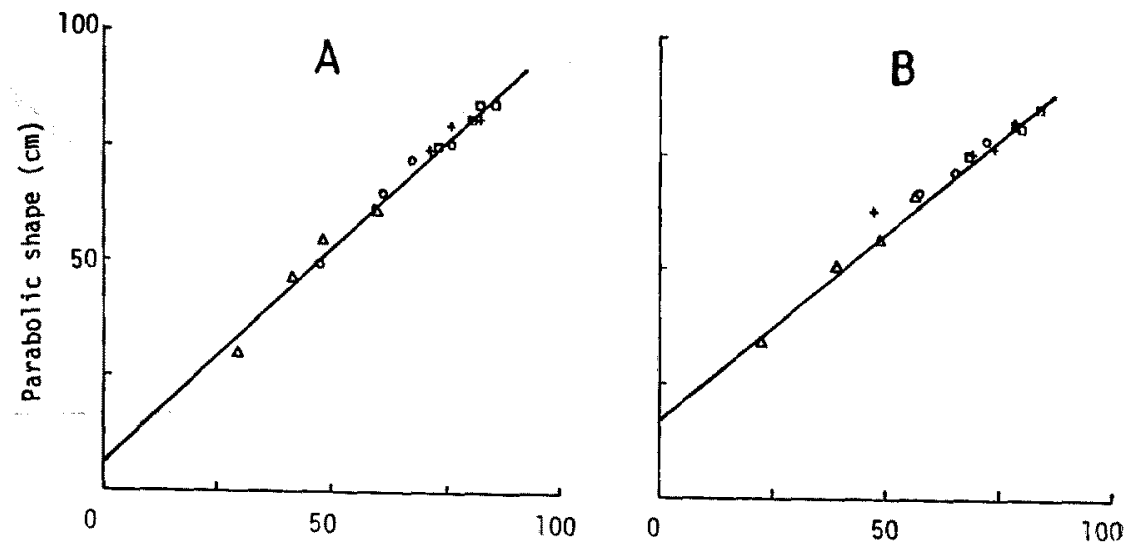

Fig. 3. Relationship between the floatline heights of semi-trammel net with vertical slack $1.1(\mathrm{~A})$, 1.5 (B) and 2.0 (C) assuming 2 different shapes. Current speed: $\square 5.6 ;+7.6 ; 09.8 ; \triangle 14.3 \mathrm{~cm} / \mathrm{s}$.

of concave shape. This relationship is shown in Fig. 3. The relationship for vertical slack 1.1 is

$$
h_{p}=5.7+0.94 h_{c}
$$

for vertical slack 1.5 is

$$
h_{p}=20.1+0.79 h_{c}
$$

while for vertical slack 2.0 is

$$
h_{p}=26.8+0.74 h_{c}
$$

Here, $h_{p}$ is the floatline height of the net when it assumes the parabolic shape while $h_{c}$ is the floatline height of the net when it assumes the concave shape.

Eqs. (9), (10) and (11) could be summarized into a single equation for estimating the floatline height of net of parabolic shape. This is done by plotting the values of the $y$-intercept and the slope of Eqs. (9), (10) and (11) against the vertical slacks, and re-calculating using regression estimate with the square root of vertical slack minus one $(\sqrt{s-1})$ as a common ordinate. A common $y$-intercept and stope can, therefore; be determined for nets of any vertical stack. The resulting equation is

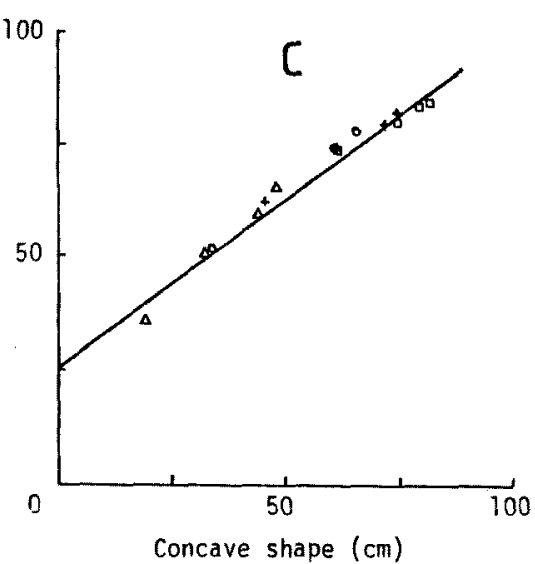

$$
h_{p}=24 \sqrt{s-1}+h_{c} e^{-0.3 \sqrt{8-1}}
$$

By substituting the observed values of $h_{c}$ to the estimated values (h) from Eq. (1), the estimated floatline height of the net of parabolic shape could be obtained using Eq. (12). Substitution is possible because the observed values are proportional to the estimated values when the semi-trammel net is of a concave shape (Fig. 2).

The estimated values of the floatline height of the net of a parabolic shape calculated from Eq. (12) was compared with those of the observed. Fig. 4 shows the relationship between the observed and estimated values for nets with different vertical slacks. At fast current, a slight overestimation was observed for vertical slack 1.1 but the difference is considered negligible (about $3 \mathrm{~cm}$ ). Aside from this, the figure reveals that a good relationship was obtained between the estimated and observed values which is, comparable to that shown in Fig. 2 for nets of concave shape.

Consequently, the floatline height of semitrammel net could be estimated in two ways depending on the direction of the current. One is by applying the modified formula (Eq. (1)) as- 

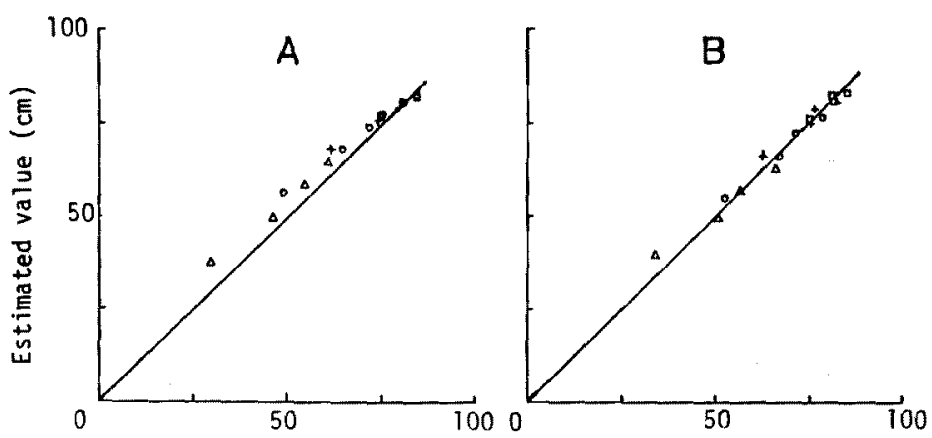

Fig. 4. Relationship between the observed and estimated floatline height of semi-trammel net with vertical slack $1.1(\mathrm{~A}), 1.5(\mathrm{~B})$, and 2.0 (C) when it assumes a parabolic shape. Current speed: $\square 5.6 ;+7.6 ; \bigcirc 9.8 ; \Delta 14.3 \mathrm{~cm} / \mathrm{s}$.

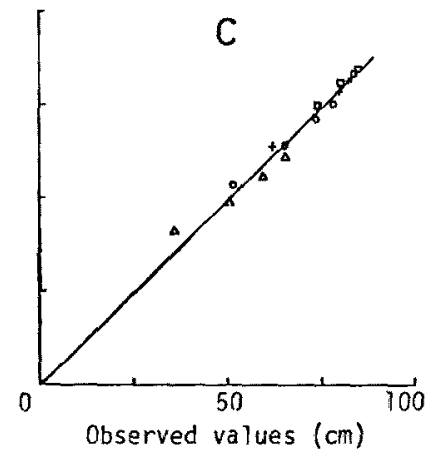

suming that the netting shape is similar to a trammel net. Another one is by using Eq. (12) taking the estimated value from the result of Eq. (1) as the $h_{c}$ value to obtain the floatline height when the net assumes a parabolic shape.

The modified formula is of practical value in designing semi-trammel or trammel nets because the effective height for the target species could be decided with precision, thus, eliminating the need of costly and time consuming trials at sea. The formula could also be useful as a subroutine in making a more precise gillnet simulation model. ${ }^{7)}$ Although, the floatline height of semi-trammel net when it assumes a parabolic shape, could be predicted using linear regression estimates, a more precise but generally applicable equation is desirable to predict its height regardless of shape or current direction considering the cross-sectional shape of the netting.

This study is partly supported by the Grant-in-
Aid for Scientific Researches of the Ministry of Education, Science and Culture of Japan under Grant: General Research (C) 63560184 (1988).

\section{References}

1) P. A. M. Stewart: Fish. Res. 6, 181-189 (1980).

2) P. A. M. Stewart and R.S. T. Ferro: Fish. Res. 3, 29-46 (1985).

3) A. L. Fridman: Theory and Design of Commercial Fishing Gear. IPST, Jerusalem, 1973, pp. 392-398.

4) K. Matuda: Fish. Res. 6, 167-179 (1988).

5) L. P. Losanes, T. Machii, K. Matuda, Y. Fujimori, and A. Koike: in "The Second Asian Fisheries Forum" (ed. by R. Hirano and I. Hanyu), The Asian Fisheries Society, Manila, 1990, pp. 805-808.

6) Y. Miyazaki: J. Tokyo Univ. Fish., 50, 105-110 (1964).

7) W. Dickson: Fish. Res. 7, 149-174 (1989). 